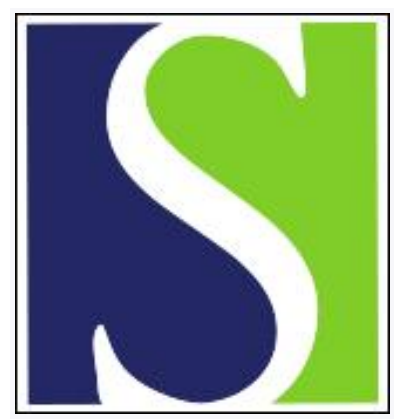

Scand J Work Environ Health 2019;45(1):22-32

https://doi.org/10.5271/sjweh.3751

Published online: 07 Nov 2018, Issue date: 01 Jan 2019

Does paid vacation leave protect against depression among working Americans? A national longitudinal fixed effects analysis

by Kim D

This study provides the first evidence on the linkage between paid vacation leave and depression and supports a protective effect among white women and women with two or more children. Policies that mandate paid vacation leave may yield substantial positive impacts on the population health and economic burden of depression among working women in the USA.

Affiliation: Department of Health Sciences, Northeastern University, 360 Huntington Avenue, 413 International Village, Boston MA 02115, USA. d.kim@northeastern.edu

Refers to the following text of the Journal: 2018;44(3):239-250

Key terms: American; depression; depressive symptom; fixed effects analysis; longitudinal; longitudinal study; mental health; paid holiday leave; paid vacation leave; stress; USA; vacation; vacation leave

This article in PubMed: www.ncbi.nlm.nih.gov/pubmed/30403822

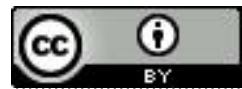




\title{
Does paid vacation leave protect against depression among working Americans? A national longitudinal fixed effects analysis
}

\author{
by Daniel Kim, MD, DrPH ${ }^{1,2}$
}

\begin{abstract}
Kim D. Does paid vacation leave protect against depression among working Americans? A national longitudinal fixed effects analysis. Scand J Work Environ Health. 2019;45(1):22-32. doi:10.5271/sjweh.3751
\end{abstract}

\begin{abstract}
Objectives The United States is the only advanced economy globally that does not guarantee its workers paid vacation leave. Although empirical studies have linked paid vacation leave to happiness and stress, no study has investigated the association between paid vacation leave and depression. Using a nationally-representative longitudinal sample of 3380 working men and women aged 45-52 years from the National Longitudinal Survey of Youth 1979, this study explored whether paid vacation leave may protect against depression.
\end{abstract}

Methods Multivariate linear and logistic regression models were employed to estimate the impacts of the number of annual paid vacation days of leave measured at age 40 on depression measured using the 7-item Center for Epidemiologic Studies Depression Scale short form (CES-D-SF) scale at age 50. Models were adjusted for demographic and socioeconomic factors, physical health, weekly hours, and individual fixed effects.

Results For every ten additional days of paid vacation leave, the odds of depression in women was $29 \%$ lower [odds ratio (OR) $0.71,95 \%$ confidence interval $(\mathrm{CI}) 0.55-0.92, \mathrm{P}=0.01$ ); there was no association in men. Linear regression models showed no association in either men or women. For every 10 days of paid leave, the odds of depression were $36 \%$ lower in White women and $38 \%$ lower in women with $\geq 2$ children.

Conclusions This study provides the first evidence on the linkage between paid vacation leave and depression, and supports a protective effect in White women with $\geq 2$ children. Should this association be truly causal, and assuming a uniform effect across all ages in working adult women, the results from this study would suggest that a hypothetical increase in the average number of days of paid vacation leave of 10 days could avoid an estimated 568442 cases of depression in women each year and lead to a cost savings of US\$2.94 billion annually. Policies that mandate paid vacation leave may have marked positive impacts on the population health and economic burden of depression among working women in the USA.

Key terms depressive symptom; longitudinal study; mental health; paid holiday leave; stress; USA.

Depression accounts for more years lost to disability than any other condition both in the United States (USA) (1) and globally (2). It affects $3-4 \%$ of workers in the USA, and as much as half of workers with depression experience short-term disability $(1,3,4)$. In addition, the economic burden attributed to depression is considerable, estimated at US\$80.4 billion in 2010 (1). The cost of depression to employers in lost work days exceeds the costs of many other common medical conditions, including heart disease, chronic obstructive lung disease, and digestive disorders (5).

Taking a vacation is plausibly linked to a lower risk of depression by providing a reprieve from work- related demands and stress and by offering opportunities for leisure activities (6). For example, vacations may help break the vicious cycle between job stressors, lack of psychological detachment from work, and job strain $(7,8)$, thereby leading to improvements in mental well-being. According to the conservation of resources theory, levels of stress increase when people experience a loss of internal resources such as time, energy and social support systems $(6,9)$. Since stress can deplete internal resources, individuals can attenuate workrelated resource losses by taking a paid vacation, that can improve stress coping mechanisms and lower stress levels (7). In turn, based on the stress-vulnerability

1 Department of Health Sciences, Northeastern University, Boston, Massachusetts, USA.

2 EHESP School of Public Health, Sorbonne Paris Cité, Paris Descartes University, Paris, France.

Correspondence to: Daniel Kim, MD, DrPH, Department of Health Sciences, Northeastern University, 360 Huntington Avenue, 413 International Village, Boston MA 02115, USA. [E-mail: d.kim@northeastern.edu]. 
model, stressors including stressful life events, along with genetic factors, psychological vulnerability, and biological factors can make individuals more vulnerable to depression (10).

Empirical studies have further demonstrated linkages between vacation leave and lower levels of stress and exhaustion $(11,12)$, higher levels of happiness (13), and depression $(14,15)$. In keeping with the conservation of resources theory, Sonnentag \& Fritz (16) have found that vacation experiences (such as psychological detachment from work and relaxation experiences) can contribute to employees' mental and physical health through providing internal and external resources. Yet to date, no studies have explored the associations between paid vacation leave and depression, indicating an important gap in the literature.

Notably, the USA is the only advanced economy globally that does not guarantee its workers any paid vacation leave (17). The federal Fair Labor Standards Act (FLSA) does not require payment for time not worked due to vacation, and paid vacation leave is a benefit based on an agreement between the employer and employee (18). By contrast, 27 of 35 OECD countries including Australia, New Zealand, and countries in the European Union currently mandate $\geq 20$ days of paid vacation per year (equivalent to 4 weeks of work based on a 5-day workweek). Meanwhile, Canada and Japan require 10 days of paid vacation and Mexico mandates 6 days of paid vacation annually (figure 1) $(19,20)$.

The argument for paid vacation leave extends beyond health to human rights: According to the United Nations' Universal Declaration of Human Rights, "Everyone has the right to rest and leisure, including reasonable limitation of working hours and periodic holidays with pay" $(6,21)$. Like paid maternity leave, for which a similar health and human rights argument has been put forth and for which political and public support is growing in the United States (22-24), there is the potential for policy change in the USA to federally mandate paid vacation leave.

Using a nationally-representative cohort of workingaged men and women in the USA, this study explored the associations between paid vacation leave and depressive symptoms and depression.

\section{Methods}

\section{Study population}

The National Longitudinal Survey of Youth 1979 (NLSY79) is an ongoing nationally-representative longitudinal study of 12686 young men and women aged 14-21 years in the USA when first surveyed in 1979, and age $45-52$ years in 2010 (median age 49 years) (25). The cohort was comprised of a cross-sectional probability sample $(\mathrm{N}=6111)$ representing the non-institutionalized civilian segment of young people living in the USA born between 1957 and 1964; supplemental samples $(\mathrm{N}=5295)$ to oversample civilian Hispanic or Latino, black, and economically disadvantaged, non-black/ non-Hispanic youths born in the same time period; and a military probability sample $(\mathrm{N}=1280)$ designed to represent the population born between 1957 and 1961 serving in the military as of 1978 . These individuals were interviewed annually through 1994 and are currently interviewed on a biennial basis on demographic, socioeconomic, and psychosocial and lifestyle factors. Study participants resided in all 50 states at baseline: 49.5\% are female, $25.0 \%$ are black, $15.8 \%$ Hispanic, and $59.2 \%$ are non-black, non-Hispanic (25). The final sample consisted of 3380 individuals who worked 30-90 hours per week at their primary job at the time of the completion of the $40+$ and $50+$ health years modules (administered at the first surveys in which the study participant turned 40 and 50 years old, respectively, with median, minimum, and maximum follow-up times of 10,8 , and 12 years), and who reported no periods of unemployment since the previous biennial interview.

\section{Outcomes}

The outcomes were based on the 7-item Center for Epidemiologic Studies Depression Scale short form (CESD-SF) asked in the $40+$ and $50+$ health modules, with total possible scores ranging from $0-21$. This scale has been previously shown to be internally consistent and to exhibit high specificity (97\%) and modest sensitivity (69\%) using a cutoff score of $\geq 8$ compared to the 20 -item CES-D scale based on the widely used cutoff score of $\geq 16$ (26). Both studies that used the CES-D cutoff point of 16 and the CES-D-SF cutoff value of $\geq 8$ have shown that women, individuals of low socioeconomic status, and those with low cognitive function are at greater risk of depression (26). As a continuous variable, the changes in the depressive symptom scores between the $40+$ and $50+$ health modules were first examined. In separate analyses, the CES-D-SF scale from the 50+ health module was used to derive a dichotomous outcome with a cutoff score of $\geq 8$ to designate onset of depression ie, depression at follow-up in individuals who were not depressed at the $40+$ module.

\section{Predictors}

As predictor variables, data was used on the number of paid vacation days at their primary job (based on the survey item "How many days of paid vacation are you entitled to each year?") assessed in the $40+$ and $50+$ 


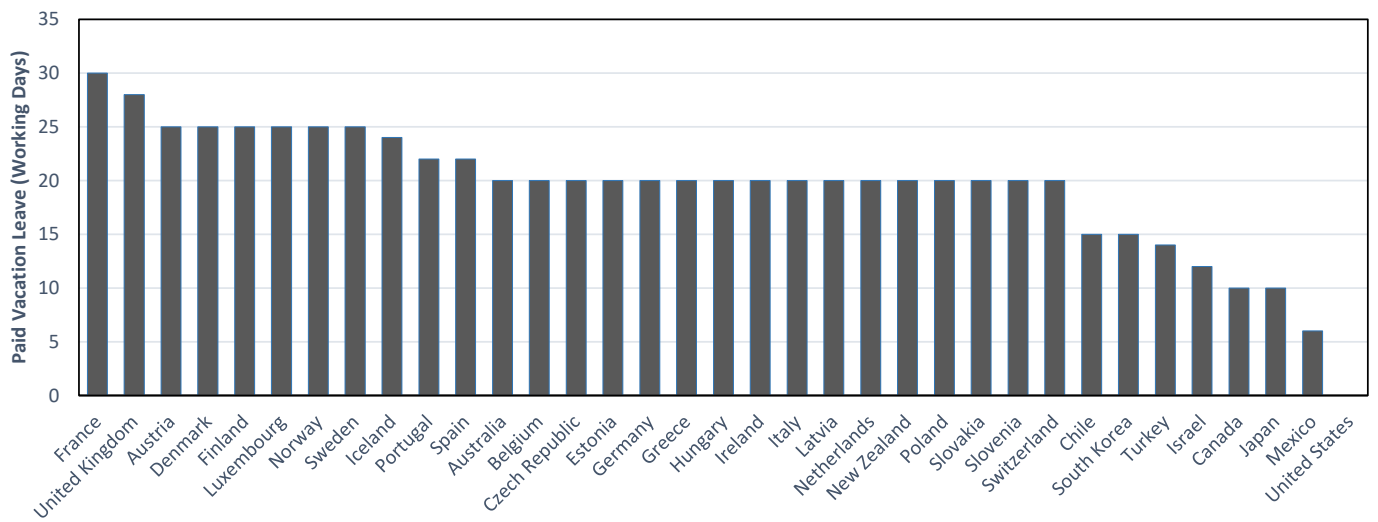

Figure 1. List of $O E C D$ countries by federally-mandated annual paid vacation leave. Source: Federation of International Employers (11), International labor Organization (12)

health modules. This was analyzed as a change in the number of paid vacation days between the $40+$ and $50+$ health modules, with rescaling to represent a change of ten additional days of paid vacation leave each year.

Model covariates consisted of age in 1998, race/ethnicity, marital status, change in total income from salary and wages (for study participant and spouse combined) between the $40+$ and $50+$ health modules, educational attainment, change in PCS-12 physical component summary score [a component of the 12-item Short Form Survey (SF-12) that measures self-reported physical health and exhibits reliability and construct validity (27)] between modules, and the change between modules in the total number of hours worked per week. In light of evidence of effect modification by gender in the logistic regression models, all models were stratified by gender.

\section{Statistical analysis}

Descriptive statistics were first calculated based on study participants included in the regression analyses. To examine the associations between the change in the number of employment-based paid vacation days and the depressive symptom/depression outcomes, both fixed effects linear and conditional logistic regression models were estimated, controlling for individual-level covariates.

A simplified fixed effects linear regression model representing the association between paid vacation days and the CES-D-SF score (as a continuous outcome variable) can be written as follows (28):

$$
Y_{i t}=\beta_{0}+\beta_{1}\left(\mathrm{X}_{i t}\right)+\beta_{2}\left(\mathrm{C}_{i t}\right)+\mathrm{u}_{i}+\lambda_{t}+\varepsilon_{i t}
$$

where $\mathbf{i}$ represents the subject and $\mathbf{t}$ represents time (year); $\mathbf{Y}$ is the outcome of the CES-D-SF depressive symptoms score; $\boldsymbol{\beta}_{\mathbf{0}}$ is the y-intercept; $\mathbf{X}$ is the time- varying exposure of paid vacation days, $\mathbf{C}$ is a timevarying covariate; $\mathbf{u}$ represents the vector of individual fixed effects (ie, a dummy variable included for each individual) that vary across individuals but not over time; $\lambda$ represents the time fixed effects (eg, times 1 and 2 ); and $\varepsilon$ represents the residual random error for each individual at each point in time.

Estimating these equations at two time-points would then correspond to the following:

$$
\begin{gathered}
Y_{i 1}=\beta_{0}+\beta_{1}\left(\mathrm{X}_{i 1}\right)+\beta_{2}\left(\mathrm{C}_{i 1}\right)+\mathrm{u}_{i}+\lambda_{1}+\varepsilon_{i 1} \\
Y_{i 2}=\beta_{0}+\beta_{1}\left(\mathrm{X}_{i 2}\right)+\beta_{2}\left(\mathrm{C}_{i 2}\right)+\mathrm{u}_{i}+\lambda_{2}+\varepsilon_{i 2}
\end{gathered}
$$

By taking the difference between equations (1) and (2) at time 1 (age 40+ module) and time 2 (age 50+ module) respectively, the individual fixed effects $\mathbf{u}$ that are constant over time difference to 0 , and we obtain the following fixed effects ("first difference") regression equation:

$$
\left(Y_{i 2}-Y_{i l}\right)=\beta_{1}\left(\mathrm{X}_{i 2}-\mathrm{X}_{i 1}\right)+\beta_{2}\left(\mathrm{C}_{i 2}-\mathrm{C}_{i 1}\right)+\left(\lambda_{2}-\lambda_{1}\right)+\left(\varepsilon_{i 2}-\varepsilon_{i 1}\right)
$$

Because the time-invariant individual factors $\mathbf{u}$ no longer appear in the model, any observed or omitted variables that are constant over time are effectively removed as confounders (28).

For conditional logistic regression, all individuals who did not change on the depression variable were excluded, difference scores for all of the time-varying covariates were created, and then logistic regression models based on maximum likelihood estimation were used to predict depression in the 50+ health module, with the difference scores as predictor variables (29).

The presence of effect modification by gender, race/ 
ethnicity, education/change in income, the change in the total number of hours worked per week, and the baseline number of children was each assessed through a Wald test to test the statistical significance of each added cross-product term for the corresponding interaction.

Dose-response relationships were then tested by grouping the change in the number of annual paid vacation days over the decade into the following categories: -355 to -20 days, -19 to -1 days, 0 days (no change), 1 to 19 days, and 20 to 355 days. A linear test for trend was performed by converting the categories into an ordinal variable and noting its corresponding P-value.

In sensitivity analyses, the robustness of the findings was explored after modifying the sample restriction based on the number of unemployed weeks and after varying the depression scale cutpoint.

To control for sample design and non-response, all models incorporated survey weights. All tests were two-tailed with a 5\% significance level. All analyses were conducted using SAS version 9.4 (SAS Institute, Cary, NC, USA).

Finally, assuming a causal effect of paid vacation leave on depression, the population attributable risks (PAR), hypothetical annual numbers of cases of depression prevented, and cost savings associated with every ten additional days of paid vacation leave were calculated.

\section{Results}

\section{Descriptive analysis}

Table 1 shows descriptive characteristics of the study samples analyzed in the fixed effects linear regression and logistic regression analyses, and compares these characteristics to the larger sample of employed individuals

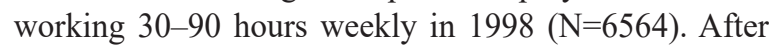
restricting the linear regression analytic sample to those with no periods of unemployment in the two years preceding the $40+$ and $50+$ health modules, and using the missing indicator method for missing observations on paid vacation days (20.8\%), education (5.6\%), and income $(14.3 \%)$, the sample size was reduced to 3380 . The linear and logistic regression analytic samples had mean ages of 36.8 and 36.9 years, respectively, in 1998, the earliest year a participant turned 40 years. Women accounted for $42.6 \%$ of the linear regression sample, while $54.2 \%$ of the logistic regression sample was female. Both study subsamples had a non-significantly greater number of mean paid vacation days than the reference sample. The linear regression sample, which had no recent periods of unemployment, as expected had a significantly higher proportion of college-educated participants and a lower mean depressive symptoms score. Conversely, the logistic regression sample, which was restricted to those with a change in depression status, had a significantly lower proportion of college-educated participants and higher mean depressive symptoms score. In total, over ten years, there were 175 incident cases of depression among women (cumulative incidence $=10.9 \%$ ) and 122 incident cases of depression among men (cumulative incidence $=6.9 \%$ ).

The change in the reported number of days of paid vacation leave in the analytic samples ranged from -355 to +355 days, with a median of 0 days. Some study participants reported either $>100$-day increases in the number of days of paid vacation or $>100$-day decreases in the number of days of paid vacation offered by their employer. While these changes are relatively large, $<1 \%$ of the analytic sample reported such changesconsistent with the roughly $1 \%$ of US employers that offer unlimited paid vacation according to the World at Work survey conducted in 2016 (30). Hence, these changes could reasonably reflect changes in one's job either to or from employers offering a relatively larger amount of paid vacation leave eg, up to an essentially unlimited number of days each year. However, because after excluding all weekends and holidays there are only 250 working weekdays in a year, all changes with absolute value $>250$ days were capped for the analysis at 250 days for positive changes and -250 days for negative changes. Nonetheless, this only affected ten observations, and all results remained unchanged to two decimal places.

Those who changed jobs between the $40+$ and $50+$ health modules showed an overall increase in the number of days of paid vacation leave. On average, this increase was significantly less than the observed increase among those who did not change jobs between the $40+$ and $50+$ health modules: a mean increase in days of paid vacation leave $=0.51$ days versus 4.39 days, respectively $(\mathrm{P}=0.01)$. Hence, in the analytic sample, a change in jobs could be a driver of the change in the number of days of paid vacation leave. At the same time, the larger increase in the number of days of paid vacation leave over time among even those who did not change jobs would appear to suggest exogenous societal changes-specifically, time trends in paid vacation leave policies by employers.

\section{Fixed effects linear regression analysis}

Table 2 presents the multivariate-adjusted coefficient estimates from fixed effects linear regression models for the association between vacation days and depressive symptoms, stratified by gender ( $\mathrm{P}$ for interaction $=0.20$ ). There was no association in men (Model 1a: $\beta=0.000568$, $\mathrm{P}=0.98$ ). In women, for every 10 days of paid vacation leave, the CES-D-SF score was 0.06 units lower (Model $1 \mathrm{~b}: \beta=-0.0581, \mathrm{P}=0.096)$. There was no evidence of effect modification by race/ethnicity (Model 2) or by education 
Table 1. Weighted descriptive characteristics of fixed effects analytic samples and comparisons to reference sample working 30-90 weekly hours in 1998. For continuous variables, the weighted means are shown. For categorical variables, the weighted proportions are shown in each category. [SD=standard deviation; CES-D-SF=Center for Epidemiologic Studies Depression Scale, short form.]

\begin{tabular}{|c|c|c|c|c|c|c|c|c|}
\hline & \multicolumn{2}{|c|}{$\begin{array}{l}1998 \text { working } \\
\text { reference sample } \\
(\mathrm{N}=6564)\end{array}$} & \multicolumn{2}{|c|}{$\begin{array}{l}\text { Fixed effects linear regression } \\
\text { analytic sample } \\
(\mathrm{N}=3380)\end{array}$} & \multirow{2}{*}{$\begin{array}{l}\text { P-value for } \\
\text { comparison } \\
\text { to reference } \\
\text { sample }^{\text {a }}\end{array}$} & \multicolumn{2}{|c|}{$\begin{array}{l}\text { Fixed effects logistic } \\
\text { regression analytic } \\
\text { sample }(\mathrm{N}=498)\end{array}$} & \multirow{2}{*}{$\begin{array}{c}\text { P-value for } \\
\text { comparison } \\
\text { to reference } \\
\text { sample }^{\text {a }}\end{array}$} \\
\hline & $\mathrm{N}(\%)$ & Mean (SD) & $\mathrm{N}(\%)$ & Mean (SD) & & $\mathrm{N}(\%)$ & Mean (SD) & \\
\hline Mean age (years) & & 37.0 & & 36.8 & $<0.01$ & & 36.9 & 0.14 \\
\hline Gender & & & & & 0.99 & & & $<0.01$ \\
\hline Male & $3768(57.4)$ & & 3768 (57.4) & & & $3006(45.8)$ & & \\
\hline Female & $2796(42.6)$ & & $2796(42.6)$ & & & $3558(54.2)$ & & \\
\hline Race/ethnicity & & & & & 0.15 & & & 0.10 \\
\hline Non-Hispanic, Non-Black & $5212(79.4)$ & & $5317(81.0)$ & & & $4949(75.4)$ & & \\
\hline Hispanic & $427(6.5)$ & & $414(6.3)$ & & & $479(7.3)$ & & \\
\hline Black & $925(14.1)$ & & $833(12.7)$ & & & $1136(17.3)$ & & \\
\hline Marital status & & & & & $<0.01$ & & & 0.16 \\
\hline Never married & $1090(16.6)$ & & $1004(15.3)$ & & & $1103(16.8)$ & & \\
\hline Married & $4083(62.2)$ & & $4437(67.6)$ & & & $3833(58.4)$ & & \\
\hline Other & $1391(21.2)$ & & $1123(17.1)$ & & & $1628(24.8)$ & & \\
\hline Education & & & & & $<0.01$ & & & 0.02 \\
\hline$<$ High school & $551(8.4)$ & & $400(6.1)$ & & & $715(10.9)$ & & \\
\hline High school /junior college & 3932 (59.9) & & $3873(59.0)$ & & & $4188(63.8)$ & & \\
\hline College or higher & $1654(25.2)$ & & $1950(29.7)$ & & & 1306 (19.9) & & \\
\hline Missing & $427(6.5)$ & & $341(5.2)$ & & & $355(5.4)$ & & \\
\hline Mean paid vacation days & & 14.4 & & 14.8 & 0.49 & & 16.6 & 0.18 \\
\hline $\begin{array}{l}\text { Mean depressive symptoms (7-ite } \\
\text { CES-D-SF) score }\end{array}$ & & 2.93 & & 2.51 & $<0.01$ & & 5.98 & $<0.01$ \\
\hline
\end{tabular}

a values are for the comparison of the mean or distribution with that of the corresponding reference sample in 1998 (the earliest year that a participant turned 40).

Table 2. Coefficient estimates from fixed effects linear regression models for longitudinal associations between paid vacation days and depressive symptoms ( $\mathrm{N}=3380$ ). All models are adjusted for age (in 1998), race/ethnicity, marital status, change in income (of study participant and spouse combined), educational attainment, change in PCS-12 physical component summary score, and change in total number of hours worked per week.

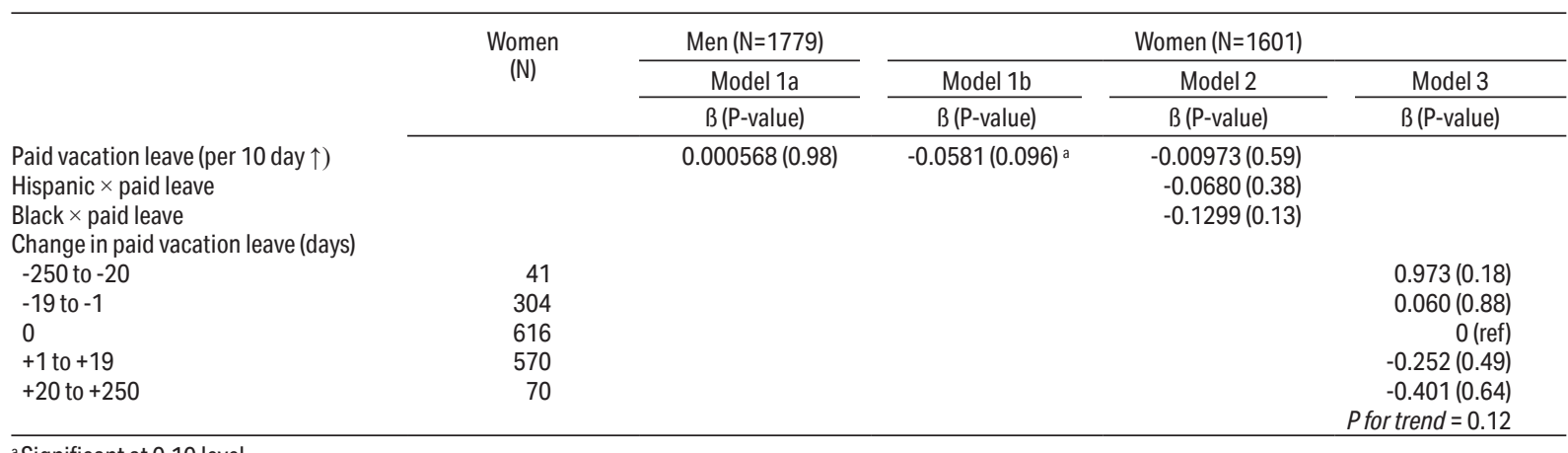

a Significant at 0.10 level.

or income (data not shown). When the change in the number of paid vacation days was categorized, there was the suggestion of a monotonic relationship, with a decrease of $>20$ paid vacation days leave annually being associated with a higher level of depressive symptoms, and an increase of $>20$ paid vacation days leave annually being associated with a lower level of depressive symptoms (Model 3; P for trend=0.12).

\section{Fixed effects logistic regression analysis}

Figure 2 shows the multivariate-adjusted coefficient estimates from fixed effects logistic regression models for the association between vacation days and depression, stratified by gender ( $\mathrm{P}$ for interaction $=0.02$ ). There was no association observed in men [odds ratio (OR) 1.07, $95 \%$ confidence interval $(\mathrm{CI}) 0.83-1.38, \mathrm{P}=0.58]$. By contrast, in women, for every ten days of paid vacation leave, the odds of depression was $29 \%$ lower (OR 0.71, $95 \% \mathrm{CI}=0.55-0.92, \mathrm{P}=0.01$ ). Among women, a significant interaction by race/ethnicity was also observed (P for interaction=0.04). In non-Hispanic, white women, for every ten days of paid vacation leave, the odds of depression were $36 \%$ lower (OR 0.64, 95\% CI $0.43-$ 0.94). Meanwhile, no association was observed among black women (OR 0.98, 95\% CI 0.89-1.09). Among 


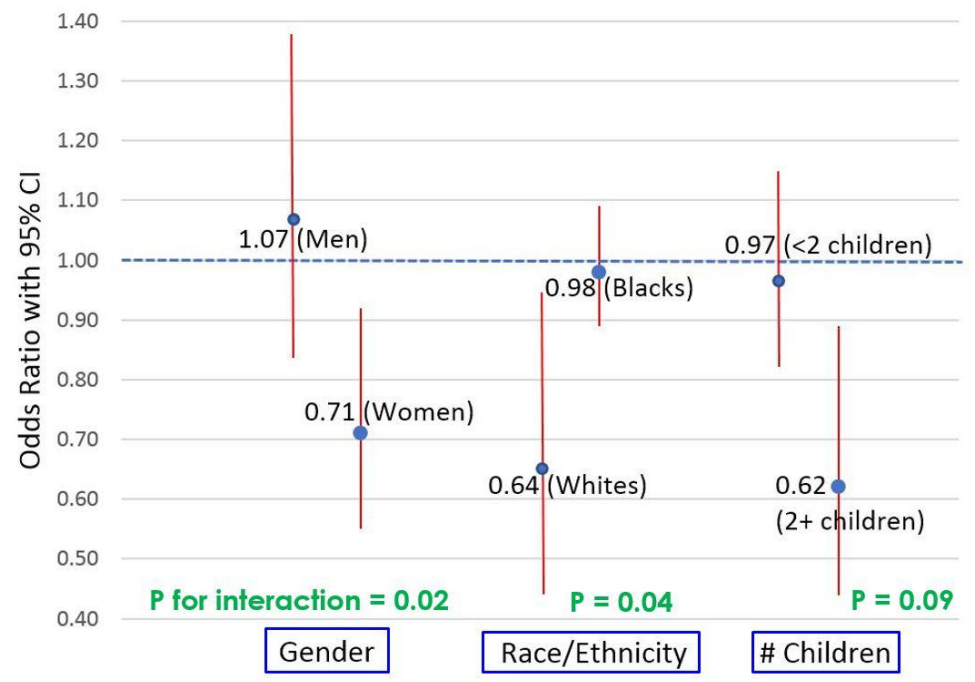

Figure 2. Stratified odds ratio estimates from fixed effects logistic regression models for longitudinal association between change in paid vacation days and depression ( $\mathrm{N}=498)$. All models are adjusted for age (in 1998), marital status, change in income (of study participant and spouse combined), educational attainment, change in PCS-12 physical componentsummaryscore, and change intotal number of hours worked per week. Genderstratified models and models are stratifed by the number of children and also adjusted for race/ethnicity. Models stratified by race/ ethnicity and number of children are restricted to women only ( $\mathrm{N}=292)$. women, there was also evidence of effect modification by the number of children. In women with $\geq 2$ children, for every ten additional days of paid vacation leave, the odds of depression was $38 \%$ lower (OR $0.62,95 \%$ CI 0.44-0.89), whereas there was no association among women with $<2$ children (OR $0.97,95 \%$ CI $0.82-1.15$; $\mathrm{P}$ for interaction $=0.09$; figure 2 ). There was no statistical evidence of effect modification by education or income (data not shown). The main effects models had moderately high concordance statistics of 0.66 and 0.64 in women and men, respectively, indicating that the models predicted the outcome of depression reasonably well and that the models were relatively well-specified.

As shown in table 3, a dose-response relationship was present, with a decrease of $>20$ paid vacation days leave annually being associated with a $>7$ times higher odds of depression (OR 7.30, 95\% CI 0.91-58.5), and an increase of $>20$ paid vacation days leave annually being associated with roughly one-third the odds of depression (OR $0.35,95 \%$ CI $0.06-2.12$ ) compared to those with no change. However, both of these point estimates did not reach statistical significance at the 0.05 level and were associated with very wide confidence intervals due to small numbers. Meanwhile, the trend was significant at the 0.10 level $\left(\mathrm{P}_{\text {trend }}=0.07\right)$.

In sensitivity analyses, the principal findings for the association between paid vacation leave and depression in women remained robust when the total number of weeks of unemployment since the $40+$ and $50+$ health modules was modified from 0 to $>5$ (OR 0.74 , $95 \%$ CI $0.57-0.95$ ) and $>10$ weeks (OR $0.73,95 \%$ CI 0.57-0.94), and alternative CES-D-SF score cut-points of 7 (OR 0.72, 95\% CI 0.57-0.91) and 9 (OR 0.71, 95\% CI 0.52-0.96) for designating depression were applied. When the analytic sample was restricted to those with no periods of unemployment since the 1998 interview, the OR point estimates remained relatively unchanged in magnitude [women $(\mathrm{N}=104)$ : $\mathrm{OR} 0.78$, 95\% CI $0.44-1.37, \mathrm{P}=0.39$; men ( $\mathrm{N}=82)$ : OR $1.02,95 \%$ CI 0.46-2.26, $\mathrm{P}=0.95]$. While the point estimate among women was statistically non-significant, this could be attributed to small numbers. Finally, the main findings were also robust when individuals with relatively large changes in the number of paid vacation days were excluded eg, $>100$-day increases or $>100$-day decreases (data not shown).

\section{Preliminary estimates of population attributable risk and associated changes in depression and economic burden}

Given an estimated prevalence of major depressive disorder (MDD) of 5.5\% in full-time workers in the United States in 2010 (1), an OR for depression of 0.711 would approximate a relative risk (RR) for depression among women for each ten additional days of paid vacation leave. Ten fewer days of paid vacation leave would hence be associated with an RR for depression of $1 / 0.711=1.406$. An estimated $39.2 \%$ of women aged $\geq 16$ years work full-time in 2010 (31). Applying the population attributable risk (PAR) formula $\mathrm{P}_{\exp } \times(\mathrm{RR}-1) /$ $\left[1+P_{\text {exp }} \times(R R-1)\right]$, where $P_{\exp }$ represents the prevalence of women who work full-time, this corresponds to a PAR among women of 0.1373 or $13.73 \%$. With 16.1 million incident cases of depression in 2015 in the United States in those aged $\geq 18$ years (32), an estimated $65.6 \%$ of these cases occurring among women (1), $39.2 \%$ of women aged $\geq 16$ working full-time (31), a PAR of $13.73 \%$, and assuming comparable effects across all adult ages, an additional ten days of paid vacation leave could potentially prevent 568442 cases of 
Table 3. Odds ratio (OR) estimates from fixed effects logistic regression models for longitudinal association between changes in paid vacation days and depression among women ( $\mathrm{N}=292)$. Model is adjusted for age (in 1998), race/ethnicity, marital status, change in income (of study participant and spouse combined), educational attainment, change in PCS-12 physical component summary score, and change in total number of hours worked per week. [Cl=confidence interval.]

\begin{tabular}{lcr}
\hline $\begin{array}{l}\text { Change in paid } \\
\text { vacation leave (days) }\end{array}$ & Number of women & OR $(95 \%$ Cl) for depression \\
\hline-250 to -20 & 10 & $7.30(0.91-58.5)$ \\
-19 to -1 & 44 & $1.45(0.44-4.71)$ \\
0 & 130 & $1($ ref $)$ \\
+1 to +19 & 95 & $1.05(0.36-3.00)$ \\
+20 to +250 & 13 & $0.35(0.06-2.12)$ \\
& & Pfor trend $=0.07^{\mathrm{b}}$ \\
\hline
\end{tabular}

a Significant at 0.10 level.

depression among women each year. Furthermore, given an estimated economic burden of MDD of US\$80.4 billion annually (1), an additional ten days of paid vacation leave could conceivably yield a cost savings of US\$2.94 billion each year. These estimates are preliminary, and should be updated after replication in other study samples that encompass working adults across all age groups.

\section{Discussion}

In this study of a nationally-representative sample of working men and women in the United States aged 33-41 years in 1998, a significant association was found between paid vacation days and the odds of depression among women. For every ten additional days of paid vacation leave, the odds of depression over a decade during mid-adult life was $29 \%$ lower. No association was observed in men. Meanwhile, there was evidence of a monotonic dose-response relationship (albeit significant only at the $10 \%$ level), along with evidence of associations among white women and women with $\geq 2$ children (although the latter was significant only at the $10 \%$ level). Findings that were significant at the $10 \%$ level are suggestive but should be interpreted more cautiously.

This study had several major strengths, including its reliance on a nationally-representative sample of working-aged adults, strengthening the generalizability of our findings within the USA; its use of longitudinal data, allowing for temporality to support causation; its employment of a previously validated depression scale, and its implementation of fixed effects analysis and control for a number of key factors including income and educational attainment to reduce confounding bias. I further estimated both multivariate linear and logistic regression models to consider alternative model specifications (including capturing potential non-linear threshold effects through logistic regression), and tested for linear dose-response relationships to support the presence of causal associations. The additional assessment of effect modification enabled the identification of subgroup differences in associations by gender, race/ethnicity, and the number of children. Finally, the study's findings were translated into population health benefits and cost savings projected to result from modifying the levels of paid vacation leave.

Does paid vacation leave have a protective causal association with depression?

To better evaluate whether paid vacation leave has a protective causal association with depression, it is useful to consider Hill's causal criteria, while recognizing that no hard-and-fast rules exist by which to judge causation (33).

Strength of association. Although the OR of depression associated with ten additional days of paid vacation leave were not strong (ie, with OR not less inverse than 0.5 ), the use of fixed effects analysis should have substantially reduced the potential for residual confounding bias. However, residual confounding such as due to time-varying employment-related factors cannot be ruled out. For example, jobs that offer few or no days of paid vacation leave might be characterized by psychosocial work environment factors that both influence continued employment in that position (and its associated benefits) as well as the risk of depression. Nonetheless, those who reported an absolute change of $\geq 20$ days of paid vacation leave did not show a significant difference in the change in income over time compared to those who experienced no change or an absolute decrease of $<20$ days in paid vacation leave. This would suggest that the estimated impact of the number of days of paid vacation leave on depression was unlikely to be prone to residual confounding by socioeconomic position. In addition, residual confounding due to socioeconomic position was reduced by controlling for educational attainment, the total number of hours worked per week, and the change in total income (for study participant and spouse combined) between the $40+$ and $50+$ health modules. Some selection bias is also possible due to attrition from the original 1979 sample (19.4\% attrition by the year 2000, 24.1\% attrition by 2010) (34). Such bias in the findings due to confounding and/or selection could be away from the null, although is unlikely to fully account for the observed findings.

Consistency. In a previous cohort study of 1500 working rural women aged 25-75 years in Wisconsin, women who took $\geq 2$ paid or unpaid vacations per year had 
a $48 \%$ lower odds of depression (OR $0.52,95 \%$ CI 0.33-0.83) compared to women who took a vacation only once every two years (15). These findings are of the same order of magnitude as what was found in the present study. To my knowledge, the present study is the first published analysis to explore paid vacation leave as a determinant of depression. Because the NLSY is a nationally-representative longitudinal sample of men and women aged 14-21 years in the USA when first surveyed in 1979, and age 45-52 years in 2010, these findings should still be replicated in additional population samples that include both younger and older age groups.

Specificity. Because depression has multiple risk factors, a strict 1:1 relationship is lacking. However, it should be noted that the absence of specificity does not rule out causation.

Temporality. While longitudinal data were used, a change in the exposure as a predictor of a change in the outcome over the same time period was examined. Hence, it is not possible to rule out reverse causation. Nonetheless, the change in paid vacation leave days was neither correlated with the change in income (Pearson $r=0.01$ ) nor the change in the number of hours worked per week (Pearson $r=-0.07$ ). Furthermore, after those who had any periods of unemployment since the previous biennial interview were excluded, the change in depressive symptoms was uncorrelated with the change in the number of weeks of unemployment (Pearson $r=0.05$ ). Collectively, this evidence suggests that depression was unlikely to have caused a significant job change with an accompanying loss of income or decline in number of weekly hours worked. This is also supported by the robust findings in sensitivity analyses when the analytic sample was restricted to those with no periods of unemployment since the 1998 interview. Hence, reverse causation appears to be an unlikely important source of bias to account for the association.

Biological gradient. Because some evidence was found for a monotonic dose-response relationship (although significant only at the $10 \%$ level), this would favor a causal association.

Plausibility/Coherence. The presence of paid vacation leave could plausibly reduce job strain (ie, paid vacation leave $\rightarrow$ lower job strain), as has been suggested by others $(7,11)$. In tandem with empirical evidence linking job strain to depression, paid vacation leave could thereby act as a protective factor against depression. To add plausibility to the association between paid vacation leave and depression, previous systematic reviews and meta-analyses have identified a significant relationship between job strain and depressive symptoms and clini- cal depression, with job strain being associated with an increased risk of clinical depression in both published (RR 1.77, 95\% CI 1.47-2.13) and unpublished analyses (RR $1.27,95 \%$ CI 1.04-1.55) $(35,36)$.

Likewise, the presence of paid vacation leave could plausibly reduce the job strain/stress associated with long working hours $(37,38)$, and thereby could attenuate the risk of depression. Long working hours have been prospectively linked to a higher risk of depressive symptoms (RR 1.66, 95\% CI 1.06-2.61) among employees working $>55$ hours/week compared with employees working 35-40 hours/week) (39), and an increased odds of MDD (OR 2.43, 95\% CI 1.11-5.30, for those working $\geq 11$ hours/day compared to employees working 7-8 hours/day) (40). A recent systematic review and meta-analysis of the prospective relation between long working hours (generally defined as $\geq 55$ hours per week) and the onset of depressive symptoms based on ten cohort studies estimated an overall positive association (RR 1.14, 95\% CI 1.03-1.25) (41). Notably, there was heterogeneity in the findings by geographic region, with an association between long working hours and depressive symptoms in Asian countries, a weaker association in Europe, and no association in North America based on three unpublished studies. However, heterogeneity was observed in the studies from North America, which might have masked significant findings (41).

Meanwhile, the presence of effect modification by race/ethnicity between white and black women could plausibly be explained on a social basis. For example, there is evidence of a higher prevalence of major depressive disorder in whites than blacks (42). This difference may be attributed in part to the presence of higher societal expectations of white women to succeed and "have it all" than black women, thereby leading to higher psychological demands in white women (43-45). In addition, paid vacation leave may provide a reprieve from work-related demands and stress (6). Consequently, paid vacation leave could plausibly buffer the impacts of higher psychological demands in white women to a greater degree than black women.

Analogy. Empirical studies have demonstrated linkages between vacation leave and lower levels of stress and exhaustion $(11,12)$ and higher levels of happiness $(13)$. Moreover, analogous to the gender differences observed in the present study, in other studies the associations between vacations and stress and mental health as well as between long working hours and depression have been shown to be stronger among women and among mothers $(7,46,47)$. Difficulty in combining work and family responsibilities has also been linked to worse self-rated health (48). Previous studies have demonstrated that women are at a higher risk of a lifetime history of major depression and a higher risk of a 12-month 
history of major depression compared to men (49). This may be attributed in part to biological differences between women and men and environmental-provoking experiences (50). Plausibly, differences in gender roles in work-family obligations may lead women to experience additional stress and burnout due to household chores and greater work-family conflict $(51,52)$, and thereby benefit more strongly than men from vacation time. The findings in the present study of an effect only among families with more than one child is consistent with this hypothesis. This potential explanatory pathway should be further explored.

Overall, of the Hill's criteria considered above, there appears to be good evidence to support a protective causal association for paid vacation leave with depression for four of the criteria (biological gradient, plausibility, coherence, and analogy), fair to good evidence to support a causal association for three criteria (strength of association, consistency, temporality), and more neutral evidence to support a causal association for one criterion (specificity, which is not an essential criterion given that depression is multifactorial). Hence, the cumulative weight of evidence based on these criteria appears to support a causal association.

A hypothetical increase in the average number of days of paid vacation leave of 10 days would raise the mean number of paid vacation days from 14.4 to 24.4 days in the United States, which would be on par with the mandated paid vacation leave in Austria, Denmark, Finland, Luxembourg, Norway, Sweden, and Iceland (figure 1) $(19,20)$. Should the association between paid vacation leave and depression be truly causal, and assuming a uniform effect across all ages in working adult women (an assumption that seems plausible given similar findings in a prior study of vacation leave and depression in women aged 25-75 years) (15), the results of the current study would suggest that such a change could have marked population health and economic benefits-with an estimated 568442 cases of depression avoided in women each year and a cost savings of US\$2.94 billion annually. These calculations assume that the projected effects based on observational data will be the same as with the introduction of such a policy on paid vacation leave, which may not be entirely accurate in the event of behavioral responses in individuals induced by new social policies $(53,54)$. For example, individuals may choose to work fewer non-vacation hours per year compared to a previous year in which vacation leave was unpaid, which in turn may have impacts on depression. In light of the above assumptions, these projections should therefore be considered preliminary.

In summary, this study provides the first published evidence on the linkage between paid vacation leave and depression in the United States. It identifies a significant protective association in women, including evidence to suggest stronger effects among white women and women with $\geq 2$ children. While the findings of this study should be replicated in other nationally-representative populations, these preliminary estimates suggest that federal policies that mandate paid vacation in the United States could have marked positive impacts on the population health and economic burden of depression among working women in the USA.

\section{Acknowledgements}

Daniel Kim is supported by grant R01 HL138247 through the National Heart, Lung, and Blood Institute at the National Institutes of Health in the United States of America. No funding source was involved in the study design, collection, analysis, interpretation of data, writing of the manuscript, or the decision to submit the manuscript for publication.

The author declares no conflicts of interest.

\section{References}

1. Greenberg PE, Fournier AA, Sisitsky T, Pike CT, Kessler RC. The economic burden of adults with major depressive disorder in the United States (2005 and 2010). J Clin Psychiatry 2015 Feb;76(2):155-62. http://dx.doi. org/10.4088/JCP.14m09298.

2. Smith K. Mental health: a world of depression. Nature 2014 Nov;515(7526):181. http://dx.doi.org/10.1038/515180a.

3. Goldberg RJ, Steury S. Depression in the workplace: costs and barriers to treatment. Psychiatr Serv 2001 Dec;52(12):1639-43. http://dx.doi.org/10.1176/appi. ps.52.12.1639.

4. University of Michigan Depression Center. Depression and lost productivity [Internet]. Ann Arbor, MI: University of Michigan; 2016. Available from: http://www. depressioncenter.org/work/information-for-employers/lostproductivity/.

5. Merikangas KR, Ames M, Cui L, Stang PE, Ustun TB, Von Korff $M$ et al. The impact of comorbidity of mental and physical conditions on role disability in the US adult household population. Arch Gen Psychiatry 2007 Oct;64(10):1180-8. http://dx.doi.org/10.1001/ archpsyc.64.10.1180.

6. Hilbrecht M, Smale B. The contribution of paid vacation time to well-being among employed Canadians. Leisure (Waterloo) 2016 Jan;40(1):31-54. http://dx.doi.org/10.1080 /14927713.2016.1144964.

7. Westman M, Eden D. Effects of a respite from work on burnout: vacation relief and fade-out. J Appl Psychol 1997 Aug;82(4):516-27. http://dx.doi.org/10.1037/00219010.82.4.516. 
8. Sonnentag S, Fritz C. Recovery from job stress: the stressor-detachment model as an integrative framework. J Organ Behav 2014 Feb;36 (S1):S72-103. http://dx.doi. org/10.1002/job. 1924 .

9. Hobfoll SE. Conservation of resources. A new attempt at conceptualizing stress. Am Psychol 1989 Mar;44(3):513-24. http://dx.doi.org/10.1037/0003-066X.44.3.513.

10. Kinser PA, Lyon DE. A conceptual framework of stress vulnerability, depression, and health outcomes in women: potential uses in research on complementary therapies for depression. Brain Behav 2014 Sep;4(5):665-74. http:// dx.doi.org/10.1002/brb3.249.

11. Etzion D. Annual vacation: duration of relief from job stressors and burnout. Anxiety Stress Coping 2003 Jun;16(2):213-26. http://dx.doi.org/10.1080/10615806.200 3.10382974 .

12. de Bloom J, Kompier M, Geurts S, de Weerth C, Taris T, Sonnentag S. Do we recover from vacation? Meta-analysis of vacation effects on health and well-being. J Occup Health 2009;51(1):13-25. http://dx.doi.org/10.1539/joh.K8004.

13. Kroesen M, Handy S. The influence of holiday-taking on affect and contentment. Ann Tour Res 2014 Mar;45:89-101. http://dx.doi.org/10.1016/j.annals.2013.12.006.

14. Tarumi K, Hagihara A. An inquiry into the causal relationship among leisure vacation, depression, and absence from work. J UOEH 1999 Dec;21(4):289-307. http://dx.doi.org/10.7888/juoeh.21.289.

15. Chikani V, Reding D, Gunderson P, McCarty CA. Vacations improve mental health among rural women: the Wisconsin Rural Women's Health Study. WMJ 2005 Aug;104(6):20-3.

16. Sonnentag S, Fritz C. The Recovery Experience Questionnaire: development and validation of a measure for assessing recuperation and unwinding from work. J Occup Health Psychol 2007 Jul;12(3):204-21. http://dx.doi. org/10.1037/1076-8998.12.3.204.

17. Ray R, Sanes M, Schmitt J. No-vacation nation revisited. Washington, D.C.: Center for Economic and Policy Research; 2013.

18. United States Department of Labor. Vacation leave [Internet]. Available from: https://www.dol.gov/general/ topic/workhours/vacation_leave.

19. Federation of International Employers. Employment law by country [Internet]. Available from: https://www.fedee.com.

20. Ghosheh N. Working conditions laws report 2012: A global review. Geneva, Switzerland: International Labour Organization; 2013.

21. United Nations. The Universal Declaration of Human Rights. New York, NY: United Nations; 1948.

22. Burtle A, Bezruchka S. Population health and paid parental leave: what the United States can learn from two decades of research. Healthcare (Basel) 2016 Jun;4(2):30. http://dx.doi. org/10.3390/healthcare4020030

23. Paquette D, Paletta DU. could get first paid family leave benefit under Trump budget proposal [Internet]. The Washington Post; 2017 May 18. Available from: https://www. washingtonpost.com/news/wonk/wp/2017/05/18/u-s-could- get-first-paid-family-leave-benefit-under-trump-plan/.

24. Horowitz JM, Parker K, Graf N. Livingston. Americans widely support paid family and medical leave, but differ over specific policies [Internet]. Pew Research Center; 2017 March 23. Available from: http://www.pewsocialtrends. org/2017/03/23/americans-widely-support-paid-familyand-medical-leave-but-differ-over-specific-policies/.

25. U.S. Bureau of Labor Statistics National Longitudinal Survey of Youth 1979: index to the NLSY79 Cohort [Internet]. U.S. Bureau of Labor Statistics; cited 2018 March 1. Available from: https://www.nlsinfo.org/content/cohorts/nlsy79.

26. Levine SZ. Evaluating the seven-item Center for Epidemiologic Studies depression scale short-form: a longitudinal U.S. community study. Soc Psychiatry Psychiatr Epidemiol 2013 Sep;48(9):1519-26. http://dx.doi. org/10.1007/s00127-012-0650-2.

27. Ware J Jr, Kosinski M, Keller SD. A 12-Item Short-Form Health Survey: construction of scales and preliminary tests of reliability and validity. Med Care 1996 Mar;34(3):220 33. http://dx.doi.org/10.1097/00005650-199603000-00003.

28. Wooldridge J. Introductory econometrics: A modern approach. Mason, TX: South-Western College Publications; 2008.

29. Allison PD. Fixed Effects Regression Methods for Longitudinal Data using SAS. Cary, NC: SAS Institute; 2005.

30. WorldatWork. Paid time off programs and practices. Washington, D.C.: WorldatWork; 2016.

31. United States Department of Labor. Women in the labor force in 2010 [Internet]. Washington, D.C.: United States Department of Labor; cited 2018 Mar 1. Available from: https://www.dol.gov/wb/factsheets/Qf-laborforce-10.htm.

32. National Institute of Mental Health. Major depression among adults [Internet]. Washington, D.C.: U.S. Department of Health and Human Services; 2017 Nov [cited 2018 Mar 1]. Available from: https://www.nimh.nih.gov/health/statistics/ prevalence/major-depression-among-adults.shtml.

33. Rothman KJ, Greenland S. Causation and causal inference in epidemiology. Am J Public Health 2005;95 Suppl 1:S144 50. http://dx.doi.org/10.2105/AJPH.2004.059204.

34. U.S. Bureau of Labor Statistics. National Longitudinal Survey of Youth 1979: retention and reasons for non-interview. Washington, D.C.: U.S. United States Department of Labor; cited 2018 Mar 1. Available from: https://www.nlsinfo. org/content/cohorts/nlsy79/intro-to-the-sample/retentionreasons-noninterview.

35. Theorell T, Hammarström A, Aronsson G, Träskman Bendz L, Grape T, Hogstedt C et al. A systematic review including meta-analysis of work environment and depressive symptoms. BMC Public Health 2015 Aug;15(1):738. http:// dx.doi.org/10.1186/s12889-015-1954-4.

36. Madsen IE, Nyberg ST, Magnusson Hanson LL, Ferrie JE, Ahola K, Alfredsson L et al.; IPD-Work Consortium. Job strain as a risk factor for clinical depression: systematic review and meta-analysis with additional individual participant data. Psychol Med 2017 Jun;47(8):1342-56. http://dx.doi.org/10.1017/S003329171600355X. 
37. Kirkcaldy BD, Trimpop R, Cooper CL. Working hours, job stress, work satisfaction and accident rates among medical practitioners, consultants and allied personnel. Int J Stress Manag 1997 Apr;4(2):79-87.

38. Smith A, Johal S, Wadsworth E et al. Stress and health at work, part IV: interim findings of the Bristol survey. Occup Health Rev 1999;80:28-31.

39. Virtanen M, Ferrie JE, Singh-Manoux A, Shipley MJ, Stansfeld SA, Marmot MG et al. Long working hours and symptoms of anxiety and depression: a 5-year follow-up of the Whitehall II study. Psychol Med 2011 Dec;41(12):248594. http://dx.doi.org/10.1017/S0033291711000171.

40. Virtanen M, Stansfeld SA, Fuhrer R, Ferrie JE, Kivimäki M. Overtime work as a predictor of major depressive episode: a 5-year follow-up of the Whitehall II study. PLoS One 2012;7(1):e30719. http://dx.doi.org/10.1371/journal. pone. 0030719 .

41. Virtanen M, Jokela M, Madsen IE, Magnusson Hanson LL, Lallukka T, Nyberg ST et al. Long working hours and depressive symptoms: systematic review and meta-analysis of published studies and unpublished individual participant data. Scand J Work Environ Health 2018 Feb;44(3):239-50. http:// dx.doi.org/10.5271/sjweh.3712.

42. Williams DR, González HM, Neighbors H, Nesse R, Abelson JM, Sweetman J et al. Prevalence and distribution of major depressive disorder in African Americans, Caribbean blacks, and non-Hispanic whites: results from the National Survey of American Life. Arch Gen Psychiatry 2007 Mar;64(3):305-15. http://dx.doi.org/10.1001/ archpsyc.64.3.305.

43. Edmondson Bell EL, Nkomo SM. Our separate ways: black and white women and the struggle for professional identity. Divers Factor 2003 Jan;11(1):11-5.

44. Arbona C, Novy DM. Career aspirations and expectations of Black, Mexican American, and White students. Career Dev Q 1991 Mar;39(3):231-9. http://dx.doi. org/10.1002/j.2161-0045.1991.tb00395.x.

45. Slaughter A. Why women still can't have it all [Internet]. Washington, D.C.: The Atlantic Magazine; 2012 July/Aug [cited 2018 May 1]. Available from: https://www.theatlantic. com/magazine/archive/2012/07/why-women-still-canthave-it-all/309020/.
46. Skinner N, Pocock B. Paid annual leave in Australia: who gets it, who takes it and implications for work-life interference. J Industr Relations 2013 Nov;55(5):681-98. http://dx.doi.org/10.1177/0022185613491680.

47. Shields M. Long working hours and health [1994-1997 data]. Health Rep 1999;11(2):33-48.

48. Luckhaupt SE, Alterman T, Li J, Calvert GM. Job characteristics associated with self-rated fair or poor health among U.S. workers. Am J Prev Med 2017 Aug;53(2):21624. http://dx.doi.org/10.1016/j.amepre.2017.03.023.

49. Kessler RC, McGonagle KA, Swartz M, Blazer DG, Nelson CB. Sex and depression in the National Comorbidity Survey. I: lifetime prevalence, chronicity and recurrence. J Affect Disord 1993 Oct-Nov;29(2-3):85-96. http://dx.doi. org/10.1016/0165-0327(93)90026-G.

50. Kessler RC. Epidemiology of women and depression. J Affect Disord 2003 Mar;74(1):5-13. http://dx.doi. org/10.1016/S0165-0327(02)00426-3.

51. Frankenhaeuser M, Lundberg U, Fredrikson M, Melin B, Tuomisto M, Myrstem A et al. Stress on and off the job as related to sex and occupational status in white-collar workers. J Organ Behav 1989 Oct;10(4):321-46. http:// dx.doi.org/10.1002/job.4030100404.

52. Westman M, Etzion D. The impact of vacation and job stress on burnout and absenteeism. Psychol Health 2001 Sep;16(5):595-606. http://dx.doi. org/10.1080/08870440108405529.

53. Kim D. Projected impacts of federal tax policy proposals on mortality burden in the United States: A microsimulation analysis. Prev Med 2018 Jun;111:272-9. http://dx.doi. org/10.1016/j.ypmed.2017.10.021.

54. Olsen A, Romig K. Modeling behavioral responses to eliminating the retirement earnings test. Soc Secur Bull 2013;73(1):39-58.

Received for publication: 30 January 2018 